\title{
THE NOVELTY EFFECT IN RECOVERED HEMINEGLECT
}

\author{
Paolo Bartolomeo
}

(INSERM Unité 324, Centre Paul Broca, Paris, France)

\begin{abstract}
Left neglect patients, patients who had recovered from left neglect and control subjects performed a task of simple motor reaction times (RTs) to lateralised visual stimuli. Neglect and recovered patients were slower than controls on left-sided targets. To explore the time course of the allocation of attention across space, an analysis of responses as a function of the serial order of the trials was performed. While neglect patients' performance did not substantially change over time, recovered patients showed a stereotyped 'novelty effect', consisting of larger left/right RT differences at the beginning of the task than at the end of it. To explain this practice-related change, a trade-off is hypothesised between the process of learning the motor task and the mechanisms involved in recovery from neglect, such as the reorienting of attention toward the contralesional side following the initial ipsilesional orienting. A possible role is proposed for the prefrontal cortex as the crucial neural structure that mediates both processes.
\end{abstract}

\section{INTRODUCTION}

Complete recovery has often been considered as the most frequent outcome of post-stroke hemineglect (Gainotti, 1968; Hier, Mondlock and Caplan, 1983; Stone, Patel, Greenwood et al., 1992). Nevertheless, evidence is accumulating that subtle spatal deficits persist in patients who had recovered from neglect (Campbell and Oxbury, 1976; Friedrich and Margolin, 1993; Goodale, Milner, Jakobson et al., 1990; Kaplan, Cohen, Rosengart et al., 1995; Karnath, 1988; Mattingley, Bradshaw, Bradshaw et al., 1994; Posner, Walker, Friedrich et al., 1984). Karnath (1988) hypothesised a multi-component model of neglect consisting of an initial, automatic orienting of attention toward the ipsilesional side, an impairment in reorienting attention toward the contralesional side and a more general, non-directional attentional deficit. The persistence of the first and third component (the initial ipsilesional orienting and the general attentional deficit) would explain the residual deficits when patients have regained some contralesional orienting abilities.

Visuospatial tasks such as the overlapping figures test are particularly suitable for disclosing the initial ipsilesional orienting component (Gainotti, D'Erme and Bartolomeo, 1991), since they do not require extensive exploratory scanning movements. As a consequence, performance on tests of this sort should remain impaired when patiens are improved on tests emphasising the exploratory-motor components. Indeed, Pizzamiglio, Antonucci, Judica et al. (1992) found that performance on a task based on the Wundt-Jastrow illusion was only slightly improved after neglect rehabilitation, while reading and cancellation tests showed 
more substantial improvements. Similar results were obtained in a longitudinal study of neglect patients who had not reccived specific rehabilitation (Mattingley et al., 1994). Left neglect patients were tested both shortly after the stroke and 12 months later. On the second testing, patients had improved on line bisection and cancellation tasks, but they still showed a strong rightward bias when identifying the expression of chimeric faces. The authors interpreted this finding as evidence of the persistence of the initial ipsilesional orienting, coupled with a more general attentional impairment, in patients who had recovered from neglect.

The present study employed a simple reaction time (RT) test to lateralised visual stimuli in order to compare the performance of left neglect patients with that of patients who had recovered from neglect and that of control subjects. An analysis of subjects' responses as a function of the serial order of the trials was performed, so as to explore the time course of the allocation of attention across space. This approach should allow to clarify at least one argument at issue, that is, to analyse the relative contributions of the initial ipsilesional orienting and the general attentional impairment to the residual spatial bias in recovered neglect patients. During the execution of a repetitive task, the two residual neglect components should affect patients' performance in two different temporal phases. The initial orienting toward the right side should manifest itself at the beginring of the task (Gainotti et al., 1991), whilst the general attentional deficit should mainly emerge at the end of the task, as a fatigue effect (Fleet and Heilman, 1986). A better understanding of these deficits may prove important for the development of rehabilitation strategies.

\section{MAterials AND Methods}

\section{Subjects}

Three groups of subjests were evaluated: five right brain-damaged patients showing signs of left hemineglect, five right brain-damaged patients who had recovered from neglect, and five normal control subjects (Table I).

Neglect was assessed using a battery of visuospatial tests (Bartolomeo, D'Erme and Gainotti, 1994), which included tasks of line cancellation, identification of overlapping figures and line bisection. A laterality score was assigned to each patient, indicating the magnitude of rightward bias. A cut-off score was determined on the basis of the performance of a group of normal control subjects (Bartolomeo et al., 1994) (Figure 1). In the recovered group, patients R3 and R5 had received a training program specific for neglect, the remaining patients exhibited a spontaneous recovery.

As it can be seen in Figure 1, some degree of residual spatial bias on paper-and-pencil tests was still present in some recovered patients at the time of RT testing. However, their performance was within the normal limits, nor did they show any clinical signs of neglect. The three groups were matched for age $(\mathrm{F}=.58$; d.f. $=2,12 ; \mathrm{p}=$ n.s. $)$ and educational level $(\mathrm{F}=1.81 ; \mathrm{df} .=2,12 ; \mathrm{p}=\mathrm{n} . \mathrm{s}$.$) . The neglect and recovered groups did not differ as for the$ duration of disease $(\mathrm{t}=-0.41$; d.f. $=7 ; \mathrm{p}=\mathrm{n} . \mathrm{s}$. $)$.

\section{Stimulus and Procedure}

Subjects sat in front of a computer monitor at a distance of approximately $50 \mathrm{~cm}$. Three horizontally arranged black circles were displayed, the central circle being located at the centre of the screen. The circles diameter subtended about $1^{\circ} 30^{\prime}$ of visual angle and the 
TABLE I

Demographical and Clinical Daza and Proportion of Left Visual Extinctions on Double Simultaneous for Neglect Patients (N1-5), Recovered Patients (R1-5) and Control Subjects (C1-5).

\begin{tabular}{ccccccc}
\hline Case & $\begin{array}{c}\text { Sex, age, years of } \\
\text { schooling }\end{array}$ & $\begin{array}{c}\text { Onset of } \\
\text { illness (days) }\end{array}$ & Etiology & $\begin{array}{c}\text { Locus of } \\
\text { lesion }\end{array}$ & Visual field & $\begin{array}{c}\text { Left visual } \\
\text { extinctions }\end{array}$ \\
\hline N1 & M, 50,7 & 306 & Ischemic & lFTP & IQ & $8 / 8$ \\
N2 & M, 77, 12 & 30 & Ischemic & lFP & Normal & $9 / 12$ \\
N3 & F, 76, 6 & 199 & Ischemic & mF & Normal & $4 / 12$ \\
N4 & M, 71, 7 & 20 & Ischemic & lFP & IQ & $3 / 4$ \\
N5 & F, 62, 15 & 90 & Ischemic & O, th & H & IQ \\
R1 & M, 74, 10 & 21 & Neoplastic & TP & Normal & $6 / 12$ \\
R2 & F, 74,8 & 485 & Neoplastic & lFP & Normal & $0 / 6$ \\
R3 & M, 75, 18 & 111 & Ischemic & mFP & SQ & $0 / 6$ \\
R4 & M, 46, 17 & 82 & Neoplastic & TP & Normal & $11 / 12$ \\
R5 & M, 58, 20 & 171 & Ischemic & lFPO & & \\
C1 & F, 69, 15 & & & & & \\
C2 & M, 70,8 & & & & & \\
C3 & M, 74, 10 & & & & & \\
C4 & F, 72, 12 & & & & & \\
\hline
\end{tabular}

$\mathrm{IQ}=$ inferior left Quadrantanopia, SQ = Superior left Quadrantanopia, H = legt Hemianopia (with macular sparing); $\mathrm{lF}=$ lateral Frontal, $\mathrm{mF}=$ medio-Frontal, $\mathrm{T}=$ Temporal, $\mathrm{P}=$ Parietal, $\mathrm{O}=$ Occipital, th $=$ thalamic. Left visual cxtinctions: number of left-side extinguished stimuli/number of bilateral simultaneous simulations (outside the visual field defects).

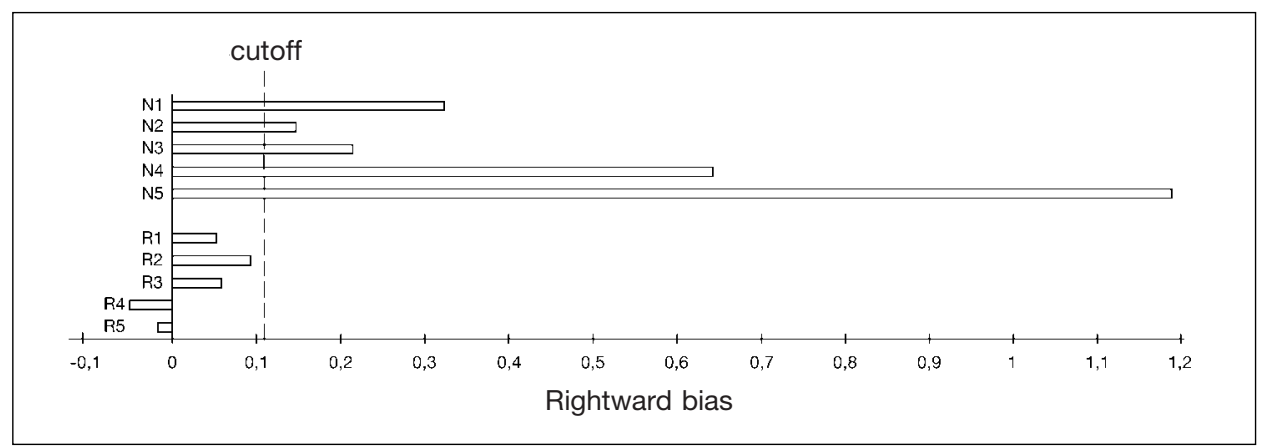

Fig. 1 - Performance of neglect patients $f N l-5)$ and recovered neglect patients (R1-5) on the visuospatial battery.

distance between circles was $1^{\circ} 50^{\prime}$. During the test, the circles were always present on the screen. Subjects were instructed to maintain fixation upon lhe central circle and to place the index finger of their right hand on the computer spacebar. After an interval varying randomly from 1000 to $2000 \mathrm{~ms}$, either the right-sided or the left-sided circle became grey. As soon as the target appeared, subjects had to respond by pressing the spacebar as quickly as possible. Response time was measured from target onset to key press. There was no time limit for responses. The target disappeared when a response was made. One block of six practice trials and ten bloclcs of four right- and four left-sided trials each were presented. The order of trials within a block was randomised. A testing session lasted approximately 2 min.

\section{RESULTS}

Subjects responded to all the targets, with the following exceptions: Subjects $\mathrm{C} 1$ and $\mathrm{C} 5$ omitted one right-side target, subject C4 omitted two left-sided targets, and patient N1 omitted three left-sided targets. Since there was no time 

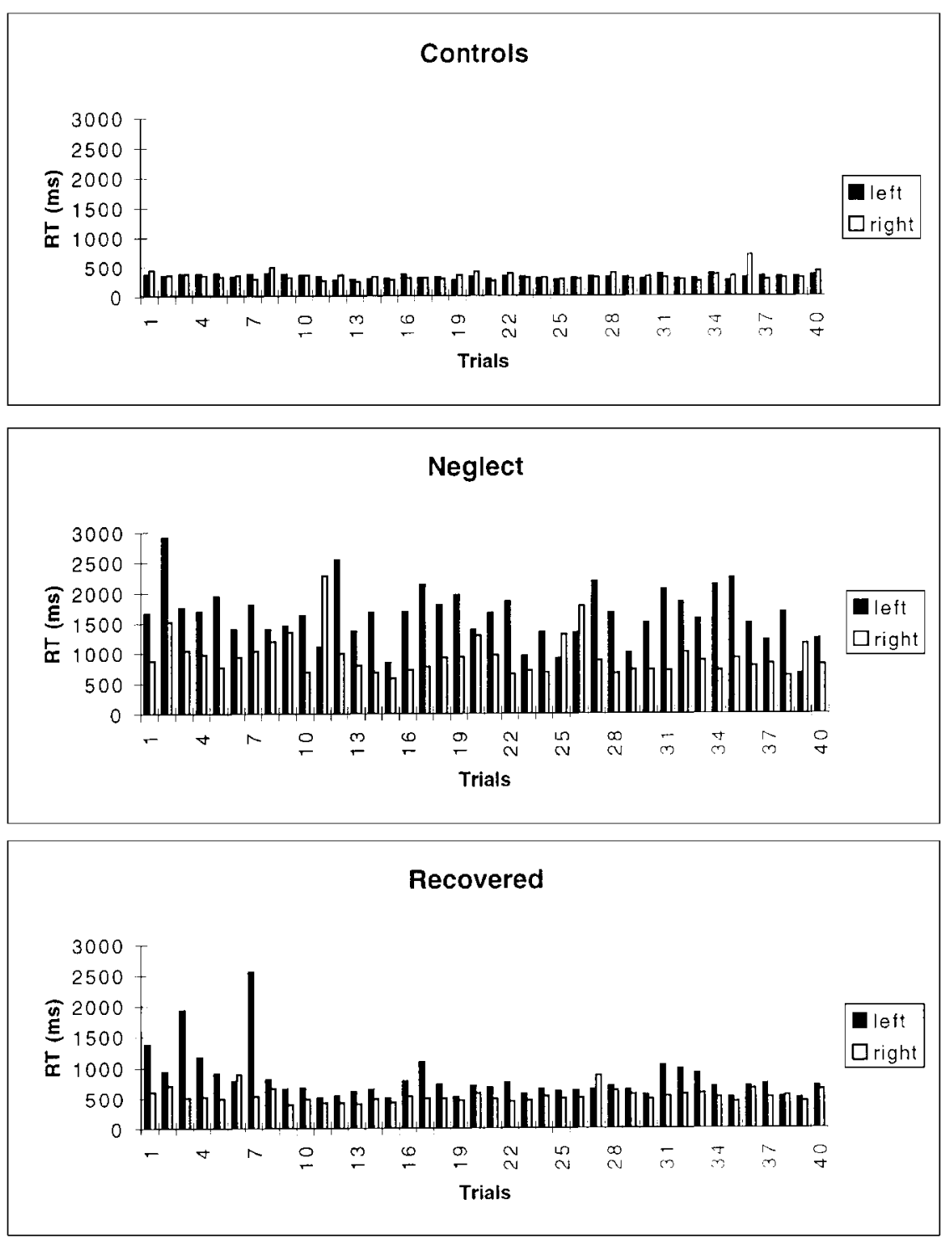

Fig. 2 - Profiles of RTs to left- and right-sided targets for control subjects, neglect patients and patients who had recovered from neglect. 
limit for responses, the rare omissions may be ascribed to anticipations or computer failure to record very long RTs. In Figure 2 the mean RT obtained by the three experimental groups are plotted as a function of the serial order of the stimuli.

A three-way repeated measures analysis of variance (ANOVA) was performed on the 15 subjects' mean RTs (Table II) on the first 20 tria1s (10 left, 10 right) and on the last 20 trials of the test, with group (neglect, recovered, control) as between factor, and target side (right, left) and test epoch (beginning, end) as within factors. Post-hoc pairwise comparisons were carried out using Fisher's protected least significant difference, with a significance level of $5 \%$. The ANOVA revealed a significant difference between groups $(F=14.87$; d.f. $=2$, $12 ; \mathrm{p}<0.001)$. The three-way interaction with group, side and test epoch was also significant $(\mathrm{F}=4.06$; d.f. $=2,12 ; \mathrm{p}<0.05)$. Post-hoc analysis revealed that neglect patients and control subjects exhibited no significant change in spatial bias over time [neglect, left targets: mean difference $(\mathrm{MD})=143 \mathrm{~ms}$, right targets: $\mathrm{MD}=197 \mathrm{~ms}$; controls, left targets: $\mathrm{MD}=38 \mathrm{~ms}$; right targets: $\mathrm{MD}=38$ ms; all comparisons, $\mathrm{p}=\mathrm{n} . \mathrm{s}$ ]. Neglect patients were slower than controls on both sides of space, both at the beginning (left targets: $\mathrm{MD}=1397 \mathrm{~ms}$; right targets: $\mathrm{MD}=680 \mathrm{~ms}$ ) and at the end of the test (left targets: $\mathrm{MD}=1292 \mathrm{~ms}$; right targets: $\mathrm{MD}=521 \mathrm{~ms}$; all comparisons, $\mathrm{p}<0.02$ ). The most critical results are those conceming recovered neglect patients. When responding to left-side targets, recovered patients were slower than controls at the beginning of the test $(\mathrm{MD}=643 \mathrm{~ms}, \mathrm{p}<0.04)$, but by the end of the session they performed in the controls' range $(\mathrm{MD}=415 \mathrm{~ms} ; \mathrm{p}=\mathrm{n}$.s.). Conversely, $\mathrm{RTs}$ to right-side targets were comparable in the recovered and in the control groups, both at the beginning $(\mathrm{MD}=222 \mathrm{~ms})$ and at the end of the test $(\mathrm{MD}=222 \mathrm{~ms} ; \mathrm{p}=\mathrm{n} . \mathrm{s}$.).

\section{DISCUSSION}

Left neglect patients, recovered neglect patients and controls performed a simple motor reaction time (RT) test to lateralised visual stimuli. Neglect patients were slower than the other subjects in responding to stimuli arising on both sides of space. The analysis of response latencies as a function of test epoch revealed that the magnitude of spatial bias showed by neglect patients and controls remained essentially unchanged over time. The recovered group performed worse-than controls on left-sided targets at the beginning of the task. However, by the end of the test recovered patients performed in the range of controls.

The slowing of responses to right (ipsilesional) targets in neglect patients, in comparison both with controls and with recovered neglect patients, might be explained by postulating that neglect patients' rightward bias was so extreme that it penalised also right-sided stimuli when they were close to the fovea. However, this is an unlikely explanation, since no stimulus was present on the rightmost part of the display iat could attract patients' attention (see, e.g., D’Erme, Robertson, Bartolomeo et al., 1992; De Renzi, Gentilini, Faglioni et al., 1989; Gainotti et al., 1991). More plausibly, the ipsilesional slowing may be 
TABLE II

Mean RTs (SD) for Neglect Patients (N1-5), Recovered Patients (R1-5) and Control Subjects (C1-5) on the Whole Test and on the Two Test Epochs (beginning: first 20 trials; end: last 20 trials)

\begin{tabular}{|c|c|c|c|c|c|c|}
\hline & \multicolumn{2}{|c|}{ Whole test } & \multicolumn{2}{|c|}{ Beginning } & \multicolumn{2}{|c|}{ End } \\
\hline & Left & Right & Left & Right & Left & Right \\
\hline N1 & 1971 (1247) & $1078(803)$ & $2359(1284)$ & $1295(769)$ & $1624(1182)$ & 988 (605) \\
\hline $\mathrm{N} 2$ & $1339(655)$ & 1001 (1059) & $1187(366)$ & 886 (427) & $1604(868)$ & 761 (309) \\
\hline N3 & $965(500)$ & 753 (299) & $842(345)$ & 623 (132) & $1062(695)$ & 863 (358) \\
\hline N4 & 2005 (1459) & $1274(893)$ & $2620(1464)$ & 1763 (1173) & 1821 (1627) & 954 (453) \\
\hline N5 & $1826(1248)$ & $588(160)$ & 1788 (1597) & $589(195)$ & 1964 (1111) & 603 (152) \\
\hline $\mathrm{Rl}$ & $966(736)$ & $513(111)$ & $1303(1043)$ & 572 (195) & $974(867)$ & $484(36)$ \\
\hline $\mathrm{R} 2$ & $1155(1410)$ & $723(510)$ & $2033(2529)$ & $1000(672)$ & $1018(442)$ & 627 (286) \\
\hline $\mathrm{R} 3$ & 402 (105) & $404(88)$ & $514(72)$ & 421 (89) & 367 (99) & 418 (111) \\
\hline $\mathrm{R} 4$ & 939 (494) & 589 (137) & 1227 (956) & 480 (94) & 832 (349) & 710 (135) \\
\hline R5 & $526(120)$ & $414(71)$ & $609(65)$ & 394 (99) & 499 (137) & 434 (65) \\
\hline $\mathrm{C} 1$ & $447(81)$ & 424 (67) & 512 (94) & $467(86)$ & $449(80)$ & 411 (44) \\
\hline $\mathrm{C} 2$ & $340(82)$ & $312(81)$ & 341 (70) & $329(88)$ & 327 (77) & $310(81)$ \\
\hline $\mathrm{C} 3$ & $166(18)$ & 241 (293) & $172(21)$ & 206 (99) & 165 (18) & 376 (575) \\
\hline $\mathrm{C} 4$ & 378 (123) & $400(161)$ & 470 (157) & 446 (183) & 312 (91) & 336 (135) \\
\hline C5 & $280(92)$ & $282(110)$ & 312 (91) & 336 (135) & 273 (109) & $255(83)$ \\
\hline
\end{tabular}

ascribed to a non-directional attentional impairment. Such a deficit has long been proposed as a component of neglect (see Robertson, 1993, for review). The present findings suggest that this putative deficit disappears with recovery of neglect, since recovered patients performed in the controls' range on rightsided targets.

If the non-direetional defieit is interpreted as an arousal defieit, it should cause a fatigue effect in neglect patients, that is, the worsening of performance over time (Fleet and Heilman, 1986). Some neglect patients did actually show an increase of rightward bias over time (Table II), but it did not reach statistical significance, possibly because of the large variance that characterised neglect patients' performance. It may well be, of course, that the overall time span of the RT task (about $2 \mathrm{~min}$ ) was too short as to elicit a fatigue effect. Alternatively, the fatigue effect and some minimal degree of progressive reorienting toward the left could have cancelled each other out. Anyway, the role of fatigue in neglect remains an open issue, as other studies (Mark and Heilman, 1988; Robertson and North, 1993) failed to demonstrate it.

Although their overall level of performance remained substantially the same, neglect patients exhibited marked fluctuations of response latencies over time (Figure 2). A dynamic interaction among several attentional deficits in neglect patients mighl account for this finding. On the contrary, the notion of a deviation of the egocentric reference as the crucial mechanism of neglect (Karnath, 1994) is more difficult to reconcile with the observed variability. Sueh a deviation, without the contribution of other mechanisms, would rather be expected to determine a uniform left/right RT difference throughout the test.

Consistent with previous observations (Friedrieh and Margolin, 1993; Posner et al., 1984), the present study shows that RT testing may reveal a residual spatial bias in patients who had recovered from neglect. The serial analysis of response latencies demonstrated that this residual bias mainly affected the initial phase of the task. Thus, recovered neglect patients showed a 'novelty effect'. 
The left-right difference decreased during the course of the test, as a result of faster responses to left-sided stimuli. Two mechanisms ean account for this process: either an orienting of patient's attention toward the left side, in which case a slowing of RTs to right targets should be expected, or a spreading of the attentional focus over the entire stimulus array (see Eriksen and Yeh, 1985), in which case response latencies to the right stimuli should not show substantial changes. Inspection of individual data (Table II) reveals that either mechanism could be at work in different patients. An altemative explanation for recovered patients' RT profile might be that they extinguished left-sided targets during the whole test, but progressively improved the strategy of responding also when nothing happened on the right side (that is, when a left-sided target was presented). This explanation is ruled out by the fact that subjects had no cue as to when the target should appear (the stimulus-onset asynchrony was random, ranging from 1000 to $2000 \mathrm{~ms}$ ). Thus, an "if not right, then left" strategy would have either led to response anticipations, which were never observed in the recovered group, or to markedly slowed RTs to left-sided targets. In particular, a subject adopting this strategy would have to wait for $2000 \mathrm{~ms}$ after display onset before concluding that no stimulus is presented on the right. As a consequence, RTs to left targets should be, on the average, at least $500 \mathrm{~ms}$ slower than RTs to right targets. However, the actual left-right difference for recovered patients at the end of the experiment was only $203.4 \mathrm{~ms}$ (see Table II). Thus, recovered patients' performance can be described as a progressive reorienting (or reshaping) of the attentional focus initially directed toward the right side. Consistent with the claims (Campbell and Oxbury, 1976; Seron, Deloche and Coyette, 1989) that recovery from neglect depends on the development of controlled strategies of visual orientation, the present results point at a crucial compensatory mechanism in the natural history of neglect, and imply that compensatory strategies are not learned once for all, but must be reprogrammed every time the patient faces a novel situation. Failure to accomplish this process may result in Sfreezing' on right-sided stimuli, which is characteristic of chronic neglect. This notion may in turn account for the poor generalisation obtained with some rehabilitation procedures (see Robertson, Halligan and Marshall, 1993, for review), and for the finding that even brief time delays interposed between cued and uncued tasks may hinder the cue effect in neglect patients (Halligan, Donegan and Marshall, 1992). If compensatory strategies are absent or insufficient, then neglect patients' performance on repetitive tasks are expected not to improve over time, because every single trial becomes a novel stimulus, which triggers an attentional orienting toward the ipsilesional side. Indeed, in a previous study (D'Erme et al., 1992) employing a simple RT paradigm we found that the mere presence of lateral position expectancy boxes caused neglect patients' performance on left-sided targets to worsen in comparison with the task condition in which stimuli were not bounded by boxes. Our interpretation was that the onset of the boxes on the screen acted as an invalid cue for left-sided targets, because right-sided boxes summoned patients' attention. Interestingly, this pattern of results was found only in severe neglect patients, and not in patients with mild neglect, who might have learned some compensatory strategies. It is tempting to relate these findings to data 
obtained in normal subjects: Yantis and Jonides (1990) showed that abrupt onsets of visual stimuli capture attention only when attention is unfocused. If the observer voluntarily attends to a stimulus, an abrupt onset at another spatial location is not able to capture his or her attention. These observations fit in a hierarchical model of attentional orienting (see Posner and Petersen, 1990), in which a frontal system, more concerned with volitional orienting, controls more posterior areas, which are in turn responsible for automatic, stimulus-driven orienting. When the anterior system is not employed, then an abrupt onset automatically captures attention through the activation of the posterior system. It may be the case that the mild neglect patients studied by D'Erme et al. (1992) were able to contrast the automatic capture of attention exerted by the rightsided box because they could use volitional orienting mechanisms. Within this framework, neglect would result from the malfunctioning of the automatic orienting mechanisms (Gainotti, Bartolomeo and D'Erme, 1992), in the absence of voluntary orienting compensation. When voluntary orienting mechanisms come into play, patients' performance may shift toward the sort of patterns shown by mild neglect patients in the study by D'Erme et al. (1992), or by recovered patients in the present study.

The described novelty effect allows some speculation about the nature and the cortical implementation of the mechanisms underlying the recovery of neglect. At the beginning of the task, the process of learning required by the novelty of the task may disrupt the reorienting mechanisms which underlie neglect recovery. Consequently, the (biased) stimulus-related orienting mechanisms prevail. As the motor task becomes more and more automatic, resources can be allocated to the compensatory reorienting mechanisms. It might be speculated that prefrontal cognitive abilities are the locus of interference between motor learning and neglect recovery. The described RT task is in fact a conditional associative task: Subjects must couple an arbitrary motor response to the appearance of two different visual targets. Evidence exists that the dorsolateral frontal cortex plays a major role in learning tasks of this sort (see, e.g., Petrides, 1991). On the other hand, frontal cognitive abilities are also important for recovery from neglect, which is more rapid in patients without injury to the right frontal cortex (Hier et al., 1983), and is related to the restoration of metabolism in the ipsi- and contralesional frontal cortices (Cappa, Perani, Paulesu et al., 1995; Pantano, Di Piero, Fieschi et al., 1992; Perani, Vallar, Paulesu et al., 1993). The notion of neglect recovery as determined by frontal cognitive abilities implies that the anterior attention system does not only act through the modulation of the posterior system, as the hierarchical hypothesis maintains (Posner and Petersen, 1990). Rather, this notion suggests that the two systems are organised in a double architecture, hierarchical and parallel.

The present data are neutral as for the laterality of the frontal cortex putatively implied in neglecl recovery. Three neglect patients and two recovered patients of the present series had a lesion involving the right lateral frontal cortex. It is perhaps of interest that one of the two recovered patients with lateral frontal lesion had received neglect rehabilitation. Training procedures for neglect might act through the activation of language-related, propositional mechanisms, likely to be subserved by the left hemisphere (Gainotti, 1996). 
To conclude, the present data are consistent with other converging evidence indicating that several attentional mechanisms interact in determining an overt hemineglect behaviour (Gainotti et al., 1991; Karnath, 1988; Mattingley et al., 1994). An impaired automatic orienting of attention appears to constitute the core deficit, as shown by its persistence even in patients clinically recovered from neglect. The use of volitional orienting mecha,isms, possibly mediated by the dorsolateral frontal cortex, may temporarily or permanently be precluded to neglect patents on account of diaschisis phenomena (Fiorelli, Blin, Bakchine et al., 1991), or because of the presence of lesions extending anteriorly or subcortically (Colombo, De Renzi and Gentilini, 1982; Hier et al., 1983; Levine, Warach, Benowitz et al., 1986).

Acknowledgements. This research was supported by the European Union grant $\mathrm{n}$. ERBCHBGCT930344. I wish to thank Prof. Guido Gainotti for helpful discussion. The assistance of Prof. J.-D. Degos, Drs. C. Loeper-Jény, A.-M. Ergis and A.-C. Bachoud-Lévi, and of administration and staff of Hôpital Henri-Mondor and Hopital Saint-Maurice, Paris, are gratefully acknowledged.

\section{REFERENCES}

Bartolomeo, P., D'Erme, P., and GainotTi, G. The relationship between visuospatial and representational neglect. Neurology, 44: 1710-1714, 1994.

CAmpBELl, D.C., and OXBURY, J.M. Recovery from unilateral visuospatial neglect. Cortex, 12: 303312, 1976.

Cappa, S.F., Perani, D., Paulesu, E., Demartin, M., Vallar, G., and Pizzamiglio, L. Hemispheric contribution to recovery of neglect after right subcortical hemispheric damage: $\mathrm{A}_{2}{ }^{15} \mathrm{O}$ PET activation study. Society for Neuroscience Abstracts, 2l: 29, 1995 (abstract).

Colombo, A., De Renzi, E., and Gentilini, M. The time course of visual hemi-inattention. Archiv für Psychiatrie und Nervenkrankheiten, 231: 539-546, 1982.

D'ERme, P., Robertson, I., Bartolomeo, P., Daniele, A., and Gainotti, G. Early rightwards orienting of attention on simple reaction time performance in patients with left-sided neglect. Neuropsychologia, 30: 989-1000, 1992.

De Renzi, E., Gentilini, M., Faglioni, P., and Barbieri, C. Attentional shifts toward the rightmost stimuli in patients with left visual neglect. Cortex, 25: 231-237, 1989.

ERIKSEN, C.W., and YEH, Y.Y. Allocation of attention in the visual field. Journal of Experimental Psychology: Human Perception and Performance, 11: 583-597, 1985.

Fiorelli, M., Blin, J., BaKchine, S., Laplane, D., and Baron, J.C. PET studies of cortical diaschisis in patients with motor hemineglect. Journal of the Neurological Sciences, 104: 135-142, 1991.

Fleet, W.S., and Heilman, K.M. The fatigue effect in hemispatial neglect. Neurology, 36 (Suppl. 1): 258, 1986 (abstract).

FrIEDRICH, F.J., and MARGOLIN, D.I. Responses time measures of hemi-inattention: a longitudinal case report Neuropsychiatry, Neuropsychology and Behavioral Neurology, 6: 54-59, 1993.

GAINOTTI, G. Les manifestations de néglicence et d'inattention pour l'hémi-espace. Cortex, 4: 6491, 1968.

GAINOTTI, G. Lateralization of brain mechanisms underlying automatic and controlled forms of spatial orienting of attention. Neuroscience and Biobehavioral Reviews, 20: 617-622, 1996.

Gainotti, G., Bartolomeo, P., and D'Erme, P. Automatic and intemational components of spatial orienting in unilateral neglect. Neuroscience Letters, 43: S50, 1992 (abstract).

Gainotti, G. D'Erme, P., and Bartolomeo, P. Early orientation of attention toward the half space ipsilateral to the lesion in patients with unilateral brain damage. Journal of Neurology, Neurosurgery and Psychiatry, 54: 1082-1089, 1991.

Goodale, M.A., Milner, A.D., Jakobson, L.S., and Carey, D.P. Kinematic analysis of limb movements in neuropsychological research: Subtle deficits and recovery of function. Canadian Journal of Psychology , 44: 180-195, 1990.

Halligan, P., Donegan, C., and Marshall, J.C. When a cue is not a cue? On the intractability of visuospatial neglect. Neuropsychological Rehabilitation, 2: 283-293, 1992.

Hier, D.B., Mondlock, J., and CaPlan, L.R. Recovery of behavioral abnormalities after right hemisphere stroke. Neurology, 33: 345-350, 1983. 
Kaplan, R.F., Cohen, R.A., Rosengart, A., Elsner, A.E., Hedges, T.R., and CaPlan, L.R. Extinction during time controlled direct retinal stimulation after recovery from right hemispheric stroke. Journal of Neurology, Neurosurgery and Psychiatry, 59: 534-536, 1995.

Karnath, H.O. Deficits of attention in acute and recovered hemi-neglect. Neuropsychologia, 20: 27$45,1988$.

KARNATH, H.O. Disturbed coordinate transformation in the neural representation of space as the crucial mechanism leading to neglect. Neuropsychological Rehabilitation, 4: 147-150, 1994.

LeVine, D.N., Warach, J.D., Benowitz, L., and Calvanio, R. Left spatial neglect: Effects of lesion size and premorbid brain atrophy on severity and recovery following right cerebral infartction. Neurology, 36: 362-366, 1986.

Mark, V.W., and HeILMAN, K.M. Does fatigue account for left peripersonal neglect? Journal of Clinical and Experimental Neuropsychology, 10: 335, 1988 (abstract).

Mattingley, J.B., Bradshaw, J.L., Bradshaw, J.A., and Nettleton, N.C. Residual rightward attentional bias after apparent recovery from right hemisphere damage: implications for a multicomponent model of neglect. Journal of Neurology, Neurosurgery and Psychiatry, 57: 597604, 1994.

Pantano, P., Di Piero, V., Fieschi, C., Judica, A., Guariglia, C., and Pizzamiglio, L. Pattern of $\mathrm{CBF}$ in the rehabilitation of visual spatial neglect. International Journal of Neurosciences, 66: 153$161,1992$.

Perani, D., Vallar, G., Paulesu, E., Alberoni, M., and Fazio, F. Left and right hemisphere contribution to recovery from neglect after right hemisphere damage. An [ $\left.{ }^{18} \mathrm{~F}\right] \mathrm{FDG}$ PET study of two cases. Neuropsychologia, 31: 115-125, 1993.

PETRIDES, M. Learning impairments following the excision of the primate frontal cortex. In S. Levin, H. M. Eisenberg and A .L. Benton (Eds. ), Frontal Lobe Function and Dysfuncion. New York: Oxford University Press, 1991, pp. 256-272.

Pizzamiglio, L., Antonucci, G., Judica, A., Montenero, P., Razzano, C., and Zoccolotti, P. Cognitive rehabililation of the hemineglect disorder in chronic patients with unilateral right brain damage. Journal of Clinical and Experimental Neuropsychology, 14: 901-923, 1992.

PosNer, M.I., and PETERSEN, S.E. The attendon system of human brain. Annual Review of Neuroscience, 13: 25-42, 1990.

PosNer, M.I., WALKER, J.A., Friedrich, P.J., and RAFAL, R.D. Effects of parietal injury on covert orienting of attention. Journal of Neuroscience, 4: 1863-1864, 1984.

RoBERTSON, I.H. The relationship between lateralised and non-lateralised attendonal deficits in unilateral neglect. In I.H. Robertson and J.C. Marshall (Eds.), Unilateral Neglect: Clinical and Experimental Studies. Hove (UK): Lawrence Erlbaum Associates, 1993, pp. 257-275.

Robertson, I.H., Halligan, P.W., and Marshall, J.C. Prospects for the rehabilitation of unilateral neglect. In I.H. Robertson and J.C. Marshall (Eds.), Unilateral Neglect: Clinical and Experimental Studies. Hove (UK): Lawrence Erlbaum Associates, 1993, pp. 279-292.

Robertson, I.H., and North, N. Fatigue versus disengagement in unilateral neglect. Journal of Neurology, Neurosurgery and Psychiatry, 56: 717-719, 1993.

Stone, S.P., Patel, P., Greenwood, R.J., and Halligan, P.W. Measuring visual neglect in acute stroke and predicting its recovery: the visual neglect recovery index. Journal of Neurology, Neurosurgery and Psychiatry, 55: 431-436, 1992.

YANTIS, S., and JonIDES, J. Abrupt visual onsets and selective attention: Voluntary versus automatic allocation. Journal of Experimental Psychology: Human Perception and Performance, 16: 121$134,1990$. 
Novelty effect and hemineglect

Novelty effect and hemineglect

Novelty effect and hemineglect

Novelty effect and hemineglect

Novelty effect and hemineglect

Novelty effect and hemineglect

Paolo Bartolomeo

Paolo Bartolomeo

Paolo Bartolomeo

Paolo Bartolomeo

Paolo Bartolomeo

Paolo Bartolomeo 